\title{
Generation and evaluation of a recombinant modified vaccinia virus Ankara vaccine for rabies
}

\author{
Jacqueline Weyer ${ }^{\mathrm{a}}$, Charles E. Rupprecht ${ }^{\mathrm{b}}$, Janet Mans ${ }^{\mathrm{c}, 1}$, Gerrit J. Viljoen ${ }^{\mathrm{c}, 2}$ and \\ Louis H. Nel ${ }^{\mathrm{a}}$
}

${ }^{a}$ University of Pretoria, Department of Microbiology and Plant Pathology, Pretoria 0002, South Africa

${ }^{\mathrm{b}}$ Centers for Disease Control and Prevention, National Center for Infectious Disease, Division of Viral and Rickettsial Zoonosis, Rabies Section, 1600 Clifton Road NE, Atlanta, GA 30333, United States

${ }^{\mathrm{c}}$ Agricultural Research Council-Onderstepoort Veterinary Institute, Division of Applied Biotechnology, Onderstepoort 0110, South Africa

\section{Abstract}

Modified vaccinia virus Ankara (MVA) has become a vaccine vector of choice for recombinant vaccine development. A MVA-based rabies vaccine would be advantageous for use as a vaccine for dogs (and wildlife), particularly if it proves innocuous and efficacious by the oral route. Here, the generation and immunological testing of a recombinant MVA expressing a rabies virus glycoprotein gene is described. In a murine model, higher dosages of recombinant MVA were needed to induce equivocal immune responses as with Vaccinia Copenhagen or Vaccinia Western Reserve recombinants, when administered by a parenteral route. The MVA recombinant was not immunogenic or efficacious when administered per os in naïve mice. The ability of the recombinant MVA to induce anamnestic responses in dogs and raccoons was also investigated. Recombinant MVA boosted humoral immune responses in these animals when administered peripherally, but not when administered orally. 


\section{Article Outline}

1. Introduction

2. Materials and methods

2.1. Viruses and cells

2.2. Animals used in the study

2.3. Construction of a MVA transfer vector and cloning of a rabies virus glycoprotein gene in different vaccinia virus vectors

2.4. Preparation of recombinant vaccinia viruses expressing rabies virus glycoprotein

2.4.1. Transfection for the generation of recombinant viruses

2.4.2. Isolation of recombinant vaccinia viruses: positive, dominant selection for mycophenolic acid resistance

2.4.3. Expression analysis: indirect fluorescent antibody test (IFA)

2.5. Immunization studies in mice

2.6. Immunization of dogs and raccoons

2.7. Virus neutralization assay: rapid fluorescent focus inhibition test

3. Results

3.1. Generation of recombinant vaccinia viruses

3.2. Humoral responses and survival in mice

3.3. Anamnestic responses in previously vaccinated dogs and raccoons

4. Discussion

Acknowledgements

References

\section{Introduction}

Rabies, a severe encephalitis of mammals, is caused by the members of the lyssavirus genus of the Rhabdoviridae family, order Mononegavirales [1]. The disease is fatal once clinical symptoms appear, and only a single case of survival of an individual without history of pre- or post-exposure vaccination has been recorded [2]. Rabies is globally endemic in domestic and/or wild animal populations, with the notable exception of a few regions where successful control and elimination strategies, of which oral vaccination had 
been a key development, were employed [3]. In countries where rabies is still endemic in domestic dogs, human exposures are primarily linked to dog bites [3] and [4]. These regions also report the vast majority of human rabies cases, estimated in the range of 55,000 annually [3] and [4]. Although effective pre- and post-exposure prophylaxes for rabies in humans are available, multiple problems hamper the effective utilization thereof in many parts of the world [5]. These include the relative high costs of cell culture vaccines and anti-rabies virus immunoglobulins, and the logistics involved in acquiring the prophylaxis, especially in rural and remote communities with poor infrastructure. The only effective strategy for the control and prevention of rabies is the control of the disease in reservoir animals, i.e. domestic dogs or wildlife species [4]. Although parenteral vaccination campaigns for dogs can achieve much success, oral vaccination could improve the coverage of vaccination campaigns in those areas where many dogs (often community owned and free-roaming) are not easily accessible for parenteral vaccination. Oral vaccination also remains the only practical approach for the vaccination of wildlife reservoirs of the disease. The alternative, the indiscriminate killing of animals, is not only socially unacceptable, but has been shown to be relatively ineffective [6]. A number of live attenuated vaccines have been evaluated as oral rabies vaccines for wildlife and for domestic dogs. These include SADBerne; SAD B19; SAD P5/88; ERA/BHK21; Vnukovo; SAG1 and SAG2, and more recently recombinant rabies virus vaccines generated by reverse genetics [7] and [8]. A recombinant vaccinia virus expressing the glycoprotein gene of the Evelyn-Rockitnicki-Abelseth strain (ERA) of rabies virus has been used as an oral vaccine for rabies in some European countries and also in the United States of America [9], [10] and [11]. As many as 75 million doses of this vaccine have been distributed for the vaccination of wildlife - at present about 10 million doses are being distributed in the USA per year [4]. The strategic use of this vaccine aided in the establishment of an "immune" barrier for rabies in raccoons (Procyon lotor) and the elimination of the disease in coyotes (Canis latrans) in the USA [12]. Although these vaccines, especially SAG2 [13] and V-RG have been used extensively, these vaccines may be improved upon. The use of the vaccinia virus-based vaccines poses some safety issues. These include adverse effects associated with vaccinia vaccines, which could be lethal in immunocompromised individuals, and the potential 
spread of the potent vaccine virus from the initial recipient to non-target recipients [4], [14] and [15]. These fears were reiterated when a pregnant woman was infected with the vaccine virus through an encounter with vaccine-laden bait and subsequently developed virus-specific lesions and related symptoms [15].

Clearly, a vaccine that could be used to immunize target animals orally but that would also be stable upon distribution and offer improved safety to target and non-target species alike would be ideal. Several factors contribute to the favorability of recombinant vaccines vectored by poxviruses: firstly, such vaccines are usually potent inducers of both arms of the immune response; secondly, the DNA genome of the virus is noninfectious and the virus relatively stable; thirdly, the poxvirus genome tolerates large insertions of foreign DNA (up to $30 \mathrm{~kb}$ ), allowing for multivalent vaccine development; finally, these vaccines are relative easy to construct with modern genetic manipulation methodology [16], [17], [18], [19] and [20]. For many years, attenuated forms or naturally host restricted members of the poxvirus group have been considered safer vectors for an effective rabies vaccine. These poxviruses in question are either naturally host restricted poxviruses, such as raccoon poxvirus; canary poxvirus and fowl poxvirus, or attenuated derivatives of vaccinia viruses such as NYVAC or modified vaccinia virus Ankara (MVA) [21]. Some of the above mentioned systems have been shown to be promising when evaluated as recombinant rabies vaccines [22], [23] and [24].

MVA has been identified as a vaccine vector of choice in many recent and ongoing vaccine development studies [25] and [26]. Additionally, MVA was used as a smallpox vaccine towards the end of the smallpox eradication effort and therefore has an established safety record for use in humans. Despite deliberate vaccination of high-risk vaccine recipients (i.e. eczematous, elderly or young), no untoward effects were reported and these reports have since been substantiated in clinical trials with MVA recombinants (e.g. [27], [28], [29] and [30]). This highly attenuated strain of vaccinia virus was prepared from material isolated from an equine, pox-lesion in Ankara (Turkey), that was serially passaged in excess of 570 times on primary chick embryo fibroblast cultures [25]. During passage on these cells, the virus adaptation resulted in six major genomic 
deletions of about 31,000 base pairs (or $15 \%$ of the wild type Vaccinia virus Ankara genome) [31] and [32]. Most of the deleted and truncated genes have been shown to be immuno-regulators, or involved in the host range of the virus and multiple gene defects will have to be corrected for reversion to wild type [32], [33], [34] and [35]. MVA virus has been proven to be phenotypically and genotypically stable and although the virus fails to productively infect most mammalian cell lines tested (including cells of human origin), recombinant genes are still efficiently expressed in non-permissive cells [34], [35], [36] and [37]. MVA delivers antigens in a highly immunogenic way to stimulate both cellular and humoral responses [38] and its efficacy as a vaccine vector has been evaluated in a myriad of infectious disease and tumor models [26], [39], [40] and [41]. Significantly, the use of MVA recombinants in the development of a prophylactic vaccine regimen for Human Immunodeficiency virus type 1, of which some recombinants are currently in clinical trails, have been described most recently [42] and [43]. Recombinant MVA expressing pre-erythocytic Plasmodium berghei antigens is also envisioned as part of vaccination regime against malaria and is also currently being evaluated in clinical trials [44], [45] and [46]. In addition, recombinant MVA viruses have been shown to be excellent boosters of vaccine induced immunity, particularly when DNA vaccine prime and recombinant MVA boost regimes are employed, but also when attenuated live vaccines are used as primary vaccine [46], [47] and [48]. In this study, the efficacy of a recombinant MVA expressing rabies virus glycoprotein as a candidate rabies vaccine was investigated. Using a murine model, the parenteral and oral immunogenicity of this MVA recombinant was compared with equivocal recombinants based on Vaccinia virus Copenhagen (Vacc Cop) and Vaccinia virus Western Reserve strain (WR). The capacity of the vaccine candidate to parenterally and orally induce anamnestic responses in previously vaccinated dogs and raccoons was also investigated.

\section{Materials and methods}

\subsection{Viruses and cells}

MVA (F6 isolate) was propagated in primary chicken embryo fibroblast culture (CEF) or BHK-21 (CCL-10). The primary CEF cultures were prepared from embryonated eggs as 
described elsewhere [49]. Recombinant and parental vaccinia WR and Vacc Cop were passaged on Vero cell cultures (CCL-81). All cell cultures used in this study were grown in Minimal Essential Medium (MEM) supplemented with $4 \mathrm{mM}$ glutamine and 2× MEM vitamin solution (all from Gibco, Invitrogen, USA). The medium was supplemented with $1 \times$ antibiotics $(100 \mu \mathrm{g} / \mathrm{ml}$ penicillin, $100 \mu \mathrm{g} / \mathrm{ml}$ streptomycin and $250 \mu \mathrm{g} / \mathrm{ml}$ amphotericin) (Gibco, Invitrogen, USA) and 10\% fetal bovine serum (FBS) (Hyclone, USA). Cultures were kept at $37{ }^{\circ} \mathrm{C}$ and at an atmosphere of $0.5 \%$ or $5 \% \mathrm{CO}_{2}$. Transfection studies were done on a primary chicken embryo cell line, CEC-32 [50].

\subsection{Animals used in the study}

$\mathrm{BALB} / \mathrm{c}$ or ICR mice (female, of different ages) were obtained from Harlan Sprague Daly (USA). Animals were housed and handled according to protocols approved by the Institutional Animal Care and Use Committee of the CDC.

2.3. Construction of a MVA transfer vector and cloning of a rabies virus glycoprotein gene in different vaccinia virus vectors

Protocols for molecular cloning of genes were followed as described elsewhere [51]. A MVA transfer vector that can be used to generate recombinant MVA with insertion in the site of deletion III, and can be used for transient selection for mycophenolic acid (MPA) resistance was generated. Relevant regions where obtained from another MVA transfer vector, pIIIdHRp7.5 [25], [52] and [53] and a Lumpy Skin Disease virus transfer vector, pLSEG [54]. Shortly, sequences flanking the site of deletion III in the MVA genome, and the early-late poxvirus promoter, $\mathrm{p} 7.5 \mathrm{~K}$ were obtained from the MVA transfer vector, pIIIdHR-p 7.5. The left flanking, flank 1 , and the $\mathrm{p} 7.5 \mathrm{~K}$ promoter sequences were digested from pIIIdHR-p7.5 with BamH I (Promega, USA) and Spe I (Promega, USA) restriction endonucleases in a double digestion reaction setup. The fragment directionally inserted into the BamH I and Xba I sites of pUC18 (Roche, Germany) to generate pUCdelIIIflank1. The right flanking sequence, flank 2, was digested from pIIIdHR-p7.5 with Kpn I (New England Biolabs) and EcoR I (Promega, USA) restriction enzymes and inserted into the Kpn I and EcoR I sites of pUC-delIIIflank1 to generate pUC-delIII. The Escherichia coli guanosine phoshoribosyl transferase (Ecogpt) resistance marker gene 
under control of the $\mathrm{p} 7.5 \mathrm{~K}$ promoter was retrieved from the pLSEG through digestion with EcoR I and inserted into the EcoR I site of the pUC-delIII clone to obtain the MVA transfer vector, pIIIp7.5gpt-JW (Fig. 1). Fragments of the expression cassette of the constructed vector were sequenced to verify integrity by using pUC/M13 universal forward and reverse primers (Promega, USA). A cDNA copy a rabies glycoprotein gene (of a isolate made from Cynictis penicillata, ARC-OVI reference number m710/90) and an enhanced green fluorescent protein gene (EGFP) of the jellyfish, Aequorea victoria (under regulation of the $\mathrm{p} 11 \mathrm{~K}$ promoter) was inserted into the BamH I site of the newly constructed MVA transfer vector, pIIIp7.5gpt-JW or the vaccinia transfer vector, pGVWRgpt-New [55], to generate pIIIp7.5-RabG-EGFP and pGVWR-RabG-EGFP. Throughout, DNA bands of interest were retrieved from agarose gels, when necessary, with the Wizard ${ }^{\circledR}$ DNA SV Gel and PCR Clean-Up system (Promega, USA) according to manufacturer's instructions. Sequencing reactions were prepared with BigDye ${ }^{\circledR}$ terminator kit (version 3.1) (Applied Biosystems, USA) as prescribed by the manufacturer and resolved on an ABI Prism 3100 automated sequencer.

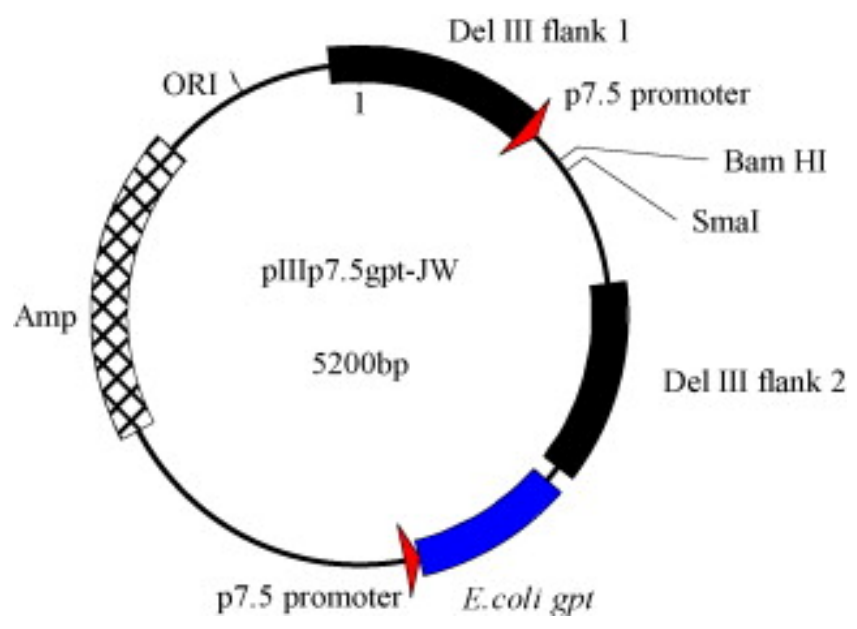

Fig. 1. A plasmid diagram of the newly constructed MVA transfer vector, pIIIp7.5gptJW. 
2.4. Preparation of recombinant vaccinia viruses expressing rabies virus glycoprotein The methods for the generation and isolation of recombinant vaccinia viruses were adapted from previously described protocols [56] and [57].

\subsubsection{Transfection for the generation of recombinant viruses}

Confluent monolayers of CEC-32 culture prepared in six well cluster cell culture plates (NUNC, Denmark) were infected with MVA or WR, respectively, at a MOI of 0.01. Virus was absorbed for $90 \mathrm{~min}$ at $37{ }^{\circ} \mathrm{C}$ and an atmosphere of $5 \% \mathrm{CO}_{2}$. Plasmid DNA was purified using spin columns (QIAquick ${ }^{\circledR}$ Gel extraction Kit, QIAGEN, Germany) and spectrophotometrically analyzed for purity and concentration. $1 \mu \mathrm{g}$ of DNA was used for the preparation of the transfection complexes with the transfection reagent, FuGene ${ }^{\circledR}$ (Roche, Germany) according to the manufacturer's suggestions. Transfection complexes prepared with pIIIp7.5-RabG-EGFP were added to the MVA infected cultures, whereas the complexes prepared with pGVWR-RabG-EGFP were added to the WR strain infected cultures. The cell cultures were incubated under standard growth conditions for $3 \mathrm{~h}$, after which the inocula were removed, the monolayers washed with phosphate buffered saline (PBS) and fed with complete medium. The plates were incubated under standard growth conditions for $48 \mathrm{~h}$.

\subsubsection{Isolation of recombinant vaccinia viruses: positive, dominant selection for mycophenolic acid resistance}

The transfected monolayers were harvested by three freeze thaw cycles. The cell culture supernatants were briefly centrifuged in a benchtop microcentrifuge and the supernatants titrated to endpoint in a ten-fold serial dilution on six well monolayers of the relevant cell

cultures. The cell culture medium was substituted with cell culture medium supplemented with $25 \mu \mathrm{g} / \mathrm{ml}$ mycophenolic acid (MPA), $250 \mu \mathrm{g} / \mathrm{ml}$ xanthine and $15 \mu \mathrm{g} / \mathrm{ml}$ hypoxanthine (all from Sigma Aldrich, Germany). After $72 \mathrm{~h}$ the infected cell cultures were observed under a fluorescence microscope for the expression of EGFP. The infected monolayers were washed with PBS and single virus plaques (in the case of WR) and foci (in the case of MVA) expressing EGFP were picked. Cell culture medium was added to yield a sample volume of $100 \mu \mathrm{l}$ and the virus material harvested by three freeze thaw 
cycles and a brief centrifugation. The harvested supernatants were diluted in a tenfold serial dilution and titrated on relevant monolayers in 12 well cell culture cluster plates under MPA selection, as before. The virus clones were processed and passaged under selection for a further 5 passages. The purification of isolates was monitored with PCR [58] and [59] using the MVAIII-5' and MVAIII-3' primer pair for the MVA recombinants [53] and VacTKl (CATATTCAGTTGATAATCG) and VacTKr (CAGCAGTTAGTTTTACCAC), targeting the TK region of vaccinia virus (WR recombinants). Virus isolates that appeared to be homogenous after PCR analysis were passaged as before but in the absence of selection. The homogeneity of these samples was confirmed with PCR and the respective recombinants were designated rMVA-RG and rWR-RG. These viruses, together with parental strains were propagated, semipurified through ultracentrifugation at $19,000 \times g$ through a $36 \%$ sucrose cushion, resuspended in MEM with $1 \times$ antibiotics, titered and stored in aliquots at $-80^{\circ} \mathrm{C}$.

\subsubsection{Expression analysis: indirect fluorescent antibody test (IFA)} Approximately, $1 \times 10^{5} \mathrm{CEF}$ or BHK-21 cells were seeded on sterile glass coverslips in six well cluster plates. Overnight monolayers were infected with the respective recombinant virus clones or wild type virus, or maintained as uninfected background control. After $48 \mathrm{~h}$ the wells were examined for EGFP fluorescence with an inverted fluorescence microscope (Orthoplan, Leitz Weitzler). Thereafter the coverslips were removed, cells fixed with ice-cold acetone for $10 \mathrm{~min}$ and flooded with diluted primary antibody (anti-rabies glycoprotein monoclonals: M725 or M778) in blocking solution ( $2 \%$ low fat milk powder, Elite, South Africa diluted in PBS). Incubation at $37^{\circ} \mathrm{C}$ for 30 min was followed by four 10 min washes in PBS with gentle rocking. Fluorescein isothiocyanate (FITC) labeled, anti-mouse IgG (Sigma-Aldrich, Germany) diluted in blocking solution with $0.01 \%$ Evan's blue was transferred to the fixed cells with $30 \mathrm{~min}$ incubation at $37{ }^{\circ} \mathrm{C}$. The incubation was followed by four 10 min washes with PBS and a final 10 min wash in distilled $\mathrm{H}_{2} \mathrm{O}$. The coverslips were air-dried, mounted on glass microscope slides in non-permanent mounting fluid (50\% glycerol, $50 \%$ PBS, pH 7.4) and visualized using a fluorescence microscope. 


\subsection{Immunization studies in mice}

Six-week-old female BALB/c or ICR mice, in groups of 10 mice, received either recombinant vaccine, rMVA-RG; rWR-RG or an experimental V-RG (recombinant VaccCop expressing rabies glycoprotein of the ERA rabies virus strain was available from Dr. C. Rupprecht, CDC). The animals received $10^{7}, 10^{8}$ or $10^{9}$ focus forming units (ffu) of recombinant MVA or $10^{7}$ plaque forming units (pfu) of rWR-RG or experimental V-RG. Control groups of 5 mice each received parental viruses, MVA ( $\left.10^{7} \mathrm{ffu}\right)$; WR or Vacc Cop $\left(10^{7} \mathrm{pfu}\right)$ or MEM $(50 \mu \mathrm{l})$. The administrations were prepared in $50 \mu 1$ MEM supplemented with $1 \times$ antibiotic mixture $(100 \mu \mathrm{g} / \mathrm{ml}$ streptomycin, $100 \mu \mathrm{g} / \mathrm{ml}$ penicillin and $250 \mu \mathrm{g} / \mathrm{ml}$ amphotericin) (Gibco, Invitrogen, USA) and administered intramuscularly in the right quadriceps muscle using a $0.5 \mathrm{cc}$ tuberculin syringe with an $8 \mathrm{~mm}$, 31-gauge needle (Becton Dickinson and Company, USA). The remaining groups received $10^{7} \mathrm{ffu}$ or pfu per os of the different recombinant viruses or controls, with the vaccine having been fed via a pipette with a barrier pipette tip. Half of the groups received booster immunizations of $10^{5} \mathrm{ffu}$ or pfu through the same route as the primary inoculation and two weeks thereafter. Blood was collected via the retro-orbital route on day 0,7 and 21 with heparinized microhematocrit capillary tubes (Becton Dickinson and Company, USA) or heparinized Natalson blood collecting capillaries (Fisher Scientific, USA). Sera were separated in Microtainer ${ }^{\circledR}$ serum separation tubes with SST $^{\text {TM }}$ (Becton Dickinson and Company, USA) as suggested by the manufacturer and stored in aliquots at $-20{ }^{\circ} \mathrm{C}$ until analysis. Animals received $10 \mathrm{MICLD}_{50}$ of rabies virus (mongoose isolate: $\mathrm{m} 710 / 90$ ) intracranially on day 28. Animals were monitored for signs of rabies for the following 30 days and collected upon death or euthanized when clinical signs appeared. Brain material of animals that succumbed in the experiment was removed aseptically and subjected to a direct fluorescent antibody test (DFA) with FITC anti-rabies monoclonal globulin (Fujirebio Diagnostic Inc.) for post-mortem diagnosis of rabies [60].

\subsection{Immunization of dogs and raccoons}

The ability of the MVA recombinant vaccine to induce an anamnestic response was tested in Beagle dogs $(n=12)$ and raccoons $(n=14)$ that were previously vaccinated with recombinant DNA vaccines and recombinant rabies virus vaccines, respectively, and 
survived street rabies virus challenge [61]. Animals were randomly assigned to experimental groups, and the investigators were blinded to the group assignment. The animals were sedated with Telazol ${ }^{\circledR}$ (Tiletamine HCL and Zolazepam HCL)(Fort Dodge, USA) anesthetic prior to the procedures and according to the manufacturer's suggestions. Raccoons and dogs received one booster dose of $10^{8}$ ffu of MVA or recombinant MVA in $1 \mathrm{ml}$ MEM per os, or $500 \mu \mathrm{l}$ intramuscularly on day 1. Other animals received mock vaccinations consisting only of MEM. The vaccine was fed to the animals with a needleless syringe for the per os administrations. Intramuscular administrations were administered in the right gastrocnemius muscle with 23-gauge needle and $1 \mathrm{ml}$ syringes (Becton Dickinson and Company, USA). Blood was collected on day 0, before administration of the vaccines, and again 7 days thereafter. With the raccoons, blood was collected through puncture of the jugular vein, and with the dogs, the animals were bled through a radial vein in the forearm. The blood was collected in Vacutainer ${ }^{\circledR}$ serum separation tubes (Becton Dickinson and Company, USA) and sera was collected and stored in aliquots at $-20^{\circ} \mathrm{C}$ prior to analysis.

2.7. Virus neutralization assay: rapid fluorescent focus inhibition test The RFFIT protocol was adapted from Smith et al. [62], but sera were set up with Challenge Virus Standard-11 as challenge in serum end-point dilutions of 8-serial, 10fold dilutions.

\section{Results}

\subsection{Generation of recombinant vaccinia viruses}

A novel MVA transfer vector was constructed and an Ecogpt marker gene, rabies glycoprotein gene and the EGFP gene (with a $\mathrm{p} 11 \mathrm{~K}$ promoter) were inserted towards the production of recombinant rMVA-RG. Towards the WR construct these genes were inserted into a vaccinia transfer vector, pGVWRgpt-New. Recombinant MVA and WR were generated by transfections of virus infected CEC-32 cell culture followed by various detection, selection and purification procedures as described in the Methods section. The purification of the recombinant virus isolates from wild type viruses was confirmed by PCR. A primer pair that binds in the regions flanking the site of deletion III on the MVA 
genome yielded a fragment of about $3500 \mathrm{bp}$ for the MVA recombinants, whereas the wild type MVA genomic DNA yielded a $700 \mathrm{bp}$ fragment in a PCR assay (data not shown). A primer pair that targets the TK region of WR was used to determine the homogeneity of recombinant vaccinia WR viruses and yielded a band of about $4500 \mathrm{bp}$ for the recombinant viruses and $400 \mathrm{bp}$ for the wild type genome (data not shown). The MVA recombinants that were generated by a single cross-over event were selected for mycophenolic acid resistance. Once the recombinant viruses were purified from parental virus background, as shown with PCR, selection pressure was lifted and subsequent passage led to the loss of the plasmid backbone and Ecogpt marker through intragenomic homologous recombination events between the double flanking regions in the recombinant virus. The isolation of marker free recombinant MVA virus could be confirmed by PCR (not shown). Expression of rabies virus glycoprotein from the recombinant viruses was confirmed by IFA with monoclonal antibodies directed to epitopes on the rabies glycoprotein (data not shown).

\subsection{Humoral responses and survival in mice}

In all experiments, the parental virus strains and MEM control groups failed to elicit virus-specific immune responses and all animals succumbed to rabies virus challenge. When administered intramuscularly, the recombinant MVA elicited detectable humoral responses only at the highest experimental doses, viz $10^{8}$ and $10^{9} \mathrm{ffu}$ (Table 1). Intramuscular doses of $10^{9} \mathrm{ffu}$ were however necessary to achieve $70-80 \%$ protection against lethal challenge (Table 1). In contrast, the experimental V-RG vaccine and the WR recombinant protected mice against lethal challenge at an intramuscular dosage of $10^{7}$ pfu with the corresponding induction of measurable immune responses (Table 1). 
Table 1.

Serological responses of mice after intramuscular administration of the vaccine and control viruses

\begin{tabular}{|c|c|c|c|c|c|}
\hline Group (dosage) & & $\begin{array}{l}\text { Day } \\
0^{\mathbf{a}}\end{array}$ & Day $7^{b}$ & Day $21^{c}$ & $\begin{array}{l}\text { \% Survivorship (number } \\
\text { animals) }\end{array}$ \\
\hline \multirow[t]{2}{*}{$\begin{array}{l}\text { rMVA-RG } \\
\left(10^{7} \mathrm{ffu}\right)\end{array}$} & $\begin{array}{l}\text { No } \\
\text { boost }\end{array}$ & $<1.0$ & $<1.0$ & $<1.0$ & $0 \%(0 / 10)$ \\
\hline & Boost & $<1.0$ & $<1.0$ & $<1.0$ & $0 \%(0 / 10)$ \\
\hline \multirow[t]{2}{*}{$\begin{array}{l}\text { rMVA-RG } \\
\left(10^{8} \mathrm{ffu}\right)\end{array}$} & $\begin{array}{l}\text { No } \\
\text { boost }\end{array}$ & $<1.0$ & $\begin{array}{l}1.34(1.34- \\
1.34)\end{array}$ & $\begin{array}{l}1.34(1.34- \\
1.34)\end{array}$ & $0 \%(0 / 10)$ \\
\hline & Boost & $<1.0$ & $\begin{array}{l}1.34(1.34- \\
1.34)\end{array}$ & $1.7(1.7-1.7)$ & $10 \%(1 / 10)$ \\
\hline \multirow[t]{2}{*}{$\begin{array}{l}\text { rMVA-RG } \\
\left(10^{9} \mathrm{ffu}\right)\end{array}$} & $\begin{array}{l}\text { No } \\
\text { boost }\end{array}$ & $<1.0$ & $\begin{array}{l}2.15(1.76- \\
2.34)\end{array}$ & $\begin{array}{l}2.18(1.92- \\
2.28)\end{array}$ & $70 \%(7 / 10)$ \\
\hline & Boost & $<1.0$ & $\begin{array}{l}2.18(1.90- \\
2.34)\end{array}$ & $\begin{array}{l}3.15(2.85- \\
3.41\end{array}$ & $80 \%(8 / 10)$ \\
\hline \multirow[t]{2}{*}{ V-RG $\left(10^{7} \mathrm{pfu}\right)$} & $\begin{array}{l}\text { No } \\
\text { boost }\end{array}$ & $<1.0$ & $\begin{array}{l}2.49(1.76- \\
2.80)\end{array}$ & $\begin{array}{l}2.96(2.11- \\
3.50)\end{array}$ & $100 \%(10 / 10)$ \\
\hline & Boost & $<1.0$ & $\begin{array}{l}1.7(1.56- \\
2.28)\end{array}$ & $\begin{array}{l}3.38(2.76- \\
4.01)\end{array}$ & $100 \%(10 / 10)$ \\
\hline \multirow[t]{2}{*}{$\begin{array}{l}\text { rWR- } \\
\text { RG(10 }\left(10^{7} \mathrm{pfu}\right)\end{array}$} & $\begin{array}{l}\text { No } \\
\text { boost }\end{array}$ & $<1.0$ & $\begin{array}{l}2.15(2.10- \\
2.30)\end{array}$ & $\begin{array}{l}2.18(2.10- \\
2.30)\end{array}$ & $70 \%(7 / 10)$ \\
\hline & Boost & $<1.0$ & $\begin{array}{l}2.08(2.08- \\
2.30)\end{array}$ & $\begin{array}{l}4.18(3.40- \\
4.28)\end{array}$ & $100 \%(10 / 10)$ \\
\hline \multirow[t]{2}{*}{ wt $\operatorname{MVA}\left(10^{7} \mathrm{ffu}\right)$} & $\begin{array}{l}\text { No } \\
\text { boost }\end{array}$ & $<1.0$ & $<1.0$ & $<1.0$ & $0 \%(0 / 5)$ \\
\hline & Boost & $<1.0$ & $<1.0$ & $<1.0$ & $0 \%(0 / 5)$ \\
\hline
\end{tabular}


openUP (June 2007)

\begin{tabular}{|l|l|l|l|l|l|}
\hline Group (dosage) & & $\begin{array}{l}\text { Day } \\
\mathbf{0}^{\mathbf{a}}\end{array}$ & Day $\mathbf{7}^{\mathbf{b}}$ & Day 21 & $\begin{array}{l}\text { \% Survivorship (number } \\
\text { animals) }\end{array}$ \\
\hline \multicolumn{7}{|l}{$\begin{array}{l}\text { Vacc Cop } \\
\left(10^{7} \mathrm{pfu}\right)\end{array}$} & $\begin{array}{l}\text { No } \\
\text { boost }\end{array}$ & $<1.0$ & $<1.0$ & $<1.0$ & $0 \%(0 / 5)$ \\
\hline & Boost & $<1.0$ & $<1.0$ & $<1.0$ & $20 \%(1 / 5)$ \\
\hline & $\begin{array}{l}\text { No } \\
\text { boost }\end{array}$ & $<1.0$ & $<1.0$ & $<1.0$ & $0 \%(0 / 5)$ \\
\hline WR $\left(10^{7}\right.$ pfu) & Boost & $<1.0$ & $<1.0$ & $<1.0$ & $0 \%(0 / 5)$ \\
\hline & $\begin{array}{l}\text { No } \\
\text { boost }\end{array}$ & $<1.0$ & $<1.0$ & $<1.0$ & $0 \%(0 / 5)$ \\
\hline MEM & Boost & $<1.0$ & $<1.0$ & $<1.0$ & $0 \%(0 / 5)$ \\
\hline
\end{tabular}

The geometric mean titers log base 10 (lowest value-highest value), as determined by RFFIT are provided. The percentage survivorship with the number of animals in the study is also tabulated.

${ }^{\text {a }}$ Naïve serum, before vaccination.

${ }^{\mathrm{b}} 7$ Days after the primary immunization.

${ }^{c} 7$ Days after the booster immunization.

Upon oral administration, the V-RG and WR vaccines offered 40-60\% protection against severe, lethal challenge (Table 2) and the survival of these animals were reflected in serum neutralizing antibody responses (Table 1 and Table 2). The recombinant MVA, however, did not elicit any detectable humoral responses in mice that received the vaccine orally (Table 2) and no animals were protected against challenge. 
Table 2 .

Serological responses of mice after oral administration of vaccine and control viruses

\begin{tabular}{|c|c|c|c|c|c|}
\hline Group & & $\begin{array}{l}\text { Day } \\
\mathbf{0}^{\mathbf{a}}\end{array}$ & Day $7^{b}$ & Day $21^{c}$ & $\begin{array}{l}\text { \% Survivorship (number } \\
\text { animals) }\end{array}$ \\
\hline \multirow[t]{2}{*}{$\begin{array}{l}\text { rMVA- } \\
\text { RG }\end{array}$} & No boost & $<1.0$ & $<1.0$ & $<1.0$ & $0(0 / 10)$ \\
\hline & Boost & $<1.0$ & $<1.0$ & $<1.0$ & $0(0 / 10)$ \\
\hline \multirow[t]{2}{*}{ V-RG } & No boost & $<1.0$ & $<1.0$ & $<1.0$ & $0(0 / 10)$ \\
\hline & Boost & $<1.0$ & $\begin{array}{l}1.14(<1.0- \\
2.18)\end{array}$ & $\begin{array}{l}1.86(<1.0- \\
2.23)\end{array}$ & $40(4 / 10)$ \\
\hline \multirow[t]{2}{*}{$\begin{array}{l}\text { rWR- } \\
\text { RabG }\end{array}$} & No boost & $<1.0$ & $\begin{array}{l}2.15(<0.1- \\
2.83)\end{array}$ & $\begin{array}{l}2.20(<0.1- \\
2.28)\end{array}$ & $40(4 / 10)$ \\
\hline & Boost & $<1.0$ & $\begin{array}{l}2.16(<0.1- \\
2.83)\end{array}$ & $\begin{array}{l}2.78(<0.1- \\
3.38)\end{array}$ & $60(6 / 10)$ \\
\hline \multirow[t]{2}{*}{ wt MVA } & No boost & $<1.0$ & $<1.0$ & $<1.0$ & $0(0 / 5)$ \\
\hline & Boost & $<1.0$ & $<1.0$ & $<1.0$ & $0(0 / 5)$ \\
\hline \multirow[t]{2}{*}{ Vacc Cop } & No boost & $<1.0$ & $<1.0$ & $<1.0$ & $0(0 / 5)$ \\
\hline & Boost & $<1.0$ & $<1.0$ & $<1.0$ & $0(0 / 5)$ \\
\hline \multirow[t]{2}{*}{ WR } & No boost & $<1.0$ & $<1.0$ & $<1.0$ & $0(0 / 5)$ \\
\hline & Boost & $<1.0$ & $<1.0$ & $<1.0$ & $0(0 / 5)$ \\
\hline \multirow[t]{2}{*}{ MEM } & No boost & $<1.0$ & $<1.0$ & $<1.0$ & $0(0 / 5)$ \\
\hline & Boost & $<1.0$ & $<1.0$ & $<1.0$ & $0(0 / 5)$ \\
\hline
\end{tabular}


The geometric mean titers log base 10 (lowest value-highest value), as determined by RFFIT are provided. All animals received $10^{7} \mathrm{ffu}$ or pfu of vaccine or control virus. The percentage survivorship with the number of animals in the study is also tabulated.

${ }^{\text {a }}$ Naïve serum, before vaccination.

${ }^{\mathrm{b}} 7$ Days after the primary immunization.

${ }^{c} 7$ Days after the booster immunization.

3.3. Anamnestic responses in previously vaccinated dogs and raccoons Following the above results, the ability of the recombinant MVA construct to elicit anamnestic responses in appropriate, and previously immunized, target animals, i.e. dogs and raccoons, was investigated. Previously vaccinated animals produced strong booster responses to the experimental MVA vaccine. The level of neutralizing antibodies was elevated up to 100-fold and 14-fold, respectively in the dogs and raccoons. However, none of the animals exhibited booster responses to the recombinant MVA when administered per os. For the controls, detectable secondary responses were absent in all animals that received parental viruses and MEM preparations administered either intramuscularly or orally (Table 3 and Table 4).

Table 3.

Anamnestic responses in beagles after administration of vaccine or control viruses

\begin{tabular}{|l|l|l|l|}
\hline Group & Day 0 & Day 7 & $\begin{array}{l}\text { Number of animals } \\
\text { in group }\end{array}$ \\
\hline rMVA-RG, intramuscular & $2.16(1.78-2.53)$ & $3.88(3.20-4.56)$ & 2 \\
\hline rMVA-RG, per os & $2.50(1.78-3.88)$ & $2.52(1.78-3.88)$ & 4 \\
\hline MVA, intramuscular & $2.20(1.81-2.60)$ & $2.60(2.50-2.67)$ & 2 \\
\hline MVA, per os & $2.02(1.88-2.16)$ & $2.01(1.85-2.16)$ & 2 \\
\hline MEM, intramuscular & 1.78 & 1.78 & 1 \\
\hline MEM, per os & 1.93 & 1.93 & 1 \\
\hline
\end{tabular}

The geometric mean titers log base 10 (lowest value-highest value), as determined by RFFIT are provided. 
Table 4.

Anamnestic responses in raccoons after administration of vaccine or control viruses

\begin{tabular}{|l|l|l|l|}
\hline Group & Day 0 & Day 7 & $\begin{array}{l}\text { Number of } \\
\text { animals in } \\
\text { group }\end{array}$ \\
\hline $\begin{array}{l}\text { rMVA-RG, } \\
\text { intramuscular }\end{array}$ & $2.91(2.64-3.18)$ & $3.83(3.78-3.88)$ & 2 \\
\hline rMVA-RG, per os & $1.82(<0.1-2.40)$ & $1.85(<0.1-2.43)$ & 6 \\
\hline MVA, intramuscular & 3.60 & 3.62 & 2 \\
\hline MVA, per os & $3.15(2.68-3.62)$ & $3.12(2.62-3.60)$ & 2 \\
\hline MEM, intramuscular & $<1.0$ & $<1.0$ & 1 \\
\hline MEM, per os & $<1.0$ & $<1.0$ & 1 \\
\hline
\end{tabular}

The geometric mean titers log base 10 (lowest value-highest value), as determined by RFFIT are provided.

\section{Discussion}

MVA has been identified as a safe and immunogenic carrier of foreign antigens and have in many applications become a vector of choice for recombinant vaccine development [25] and [26]. The use of MVA as vaccine carrier has been extensively investigated in a number of disease models and its potential as vaccine carrier shown in several clinical trials employing different regimens of administration. Based on this accumulated evidence, it was a worthwhile objective to investigate the potential of a candidate recombinant MVA rabies vaccine as an alternative to the commercial vaccinia virusbased rabies virus vaccine, V-RG.

To our knowledge, this is the first demonstration of construction of resistance markerfree recombinant MVA using the principles of transient marker stabilization with the 
Ecogpt gene as a marker - as previously described for other vaccinia virus strains [63]. The construction of marker-free recombinants is an important consideration if commercialization of such a recombinant as a vaccine is considered. An EGFP gene was also included in the construct. The use of EGFP for the screening of recombinants eliminates the need for colorimetric substrates and the application of other reagents to visualize the recombinant foci and only requires the use of a fluorescent microscope. Expression of rabies glycoprotein from rMVA-RG, rWR-RG and the experimental V-RG was verified with an IFA employing monoclonals.

The recombinant MVA vaccine expressing a rabies virus glycoprotein gene, rMVA-RG, was initially tested in mice. It was found to be effective in mice when administered peripherally, but protection was only attained at doses of rMVA-RG virus as high as $10^{9} \mathrm{ffu}$. Indeed, the level of humoral immune responses clearly correlated with the dosage of recombinant MVA vaccine administered and only at a dosage of $10^{9} \mathrm{ffu}, 10$-fold or higher boosts of virus neutralizing antibodies were observed. The contrast in efficacy between this MVA candidate and the experimental V-RG and WR recombinants was evident through all of the experimental procedures, with the latter two vaccinia recombinants providing full protection at doses of $10^{7} \mathrm{pfu}$. At these doses and in agreement with previous observations [38], the titers of virus neutralizing antibodies induced by these two recombinant vaccinia virus vaccines were comparable.

Critically, the recombinant MVA failed to elicit any detectable humoral responses upon oral administration of high doses and afforded no protection in our murine model. Although more successful in this regard, the experimental V-RG and WR strain recombinants also did not provide full protection for all animals challenged with rabies virus. Since these vaccines have known efficacy in other models by the oral route, we concluded that our murine model was suboptimal for the testing of these oral vaccines against rabies and extended our investigation to include two species known to be susceptible to oral immunization with the vaccinia-based rabies vaccine, V-RG, viz. dogs and raccoons. However, when administrated orally, MVA recombinants also failed to elicit memory responses in previously vaccinated dogs and raccoons. In contrast, when 
administered intramuscularly, the MVA recombinant enhanced immune responses in both species, boosting neutralizing antibody levels up to a 100-fold in pre-vaccinated and challenged raccoons and dogs. This finding appears to be in line with others, such as a study involving recombinant MVA expressing measles virus antigens, where MVA recombinants boosted low-levels of vaccine induced immunity much more efficiently than live attenuated measles virus vaccine [64]. Booster responses induced by MVA recombinants upon mucosal delivery, specifically after intranasal delivery, have also been indicated in macaques [65] and [66]. The most prominent value of recombinant MVA vaccines lie in this so-called "booster effect". As such, recombinant MVA have potential application in the field if used in conjunction with current live attenuated vaccines to attain long lasting protective responses. On the other hand, used as a primary vaccine, multiple doses may be required to attain efficacy upon peripheral administrations [67]. Although successful vaccination through intragastric intubation with MVA recombinants and the efficacy of MVA recombinants via other mucosal routes have been shown in a number of studies [68] and [69], successful vaccination directly via the oral route has not yet been investigated to our knowledge. An important part of the scope of this study was therefore to specifically determine the oral innocuity and immunogenicity of the rabies glycoprotein recombinant MVA.

The failure of oral immunization with MVA recombinants used in this study is most likely the result of the severe attenuation of the vaccine carrier leading to its lack of replication in the vaccine recipient. Considering the mechanics of mucosal administration of the vaccine virus, much virus is likely to be "lost" due to sloughing of cells in the mouth and throat. In the case of the V-RG and WR recombinant, the viruses are thought to be able to readily infect and replicate in these tissues, which may explain its potency via this route. A recombinant MVA vaccine may still be of use if included in immunization schemes in the presence of maternally derived antibodies (for example against rabies virus) or in the presence of pre-existing immunity to vaccinia virus. These constructs might therefore have a potential for the vaccination of younger animals with maternally derived immunity or previously vaccinated animals that require boosting [70]. The specific use of such recombinants in immunocompromised individuals has also been 
suggested and remains to be evaluated [71]. In conclusion, the immunogenicity and safety of recombinant MVA expressing rabies virus glycoprotein has been shown in this study. The recombinant vaccine proved immunogenic upon peripheral administration in mice, dogs and raccoons and the booster potential of MVA recombinants has also been confirmed in the application described here. However, increased safety came at the cost of efficacy and the lack of oral innocuity of the recombinant MVA rabies glycoprotein would rule this candidate unsuitable for replacement of V-RG or other effective oral rabies vaccines.

\section{References}

[1] N. Tordo, A. Benmansour, C. Calisher, R.G. Dietzgen, R.-X. Fang and A.O. Jackson

et al., Lyssaviruses. In: C.M. Fauquet, M.A. Mayo, J. Maniloff, U. Desselberger and L.A. Ball, Editors, Virus taxonomy: the classification and nomenclature of viruses. The 8th report of the International Committee on Taxonomy of Viruses, Oxford Academic, San Diego (2005), pp. 623-629.

[2] R.E. Willoughby, K.S. Tieves, G.M. Hoffman, N.S. Ghanayem, C.M. Amlie-Lefond and M.J. Schwabe et al., Survival after treatment of rabies with induction of coma, $N$ Engl J Med 352 (2005), pp. 2508-2514.

[3] Anonymous. World Survey for Rabies No 35 for the year 1999.

WHO/CD/CSR/EPH/2002.10. World Health Organization, Geneva, 2002.

[4] Anonymous. World Health Organization Expert Consultation on Rabies: First report. World Health Organization Technical report series 931. World Health Organization, Geneva, 2005, pp. 15-19.

[5] C.E. Rupprecht and R.V. Gibbons, Prophylaxis against rabies, $N$ Engl J Med 351 (2004), pp. 2626-2635. 
[6] J.G. Debbie, Rabies control of terrestrial wildlife by population reduction. In: G.M. Baer, Editor, The Natural History of Rabies (2nd ed.), CRC Press, Boca Raton \& Ann Arbor \& Boston (1991), pp. 477-484.

[7] Anonymous. Field application of oral rabies vaccines for dogs: report of a WHO consultation organized in collaboration with the Office International des Epizooties (OIE). World Health Organization, Geneva, 1998; WHO/EMC/ZDI/98, 15.

[8] C.E. Rupprecht, C.A. Hanlon, J. Blanton, J. Manangan, P. Morrill and S. Murphy et al., Oral vaccination of dogs with recombinant rabies virus vaccines, Vir Res 111 (2005) (1), pp. 101-105.

[9] M.-P. Kieny, R. Lathe, R. Drillien, D. Spehner, S. Shory and D. Schmitt et al., Expression of rabies virus glycoprotein from a recombinant vaccinia virus, Nature $\mathbf{3 1 2}$ (1984), pp. 163-166.

[10] T.J. Wiktor, R.I. MacFarlan, K.J. Reagen, B. Dietschold, P.J. Curtis and W.H. Wunner et al., Protection from rabies by a vaccinia virus recombinant containing the rabies virus glycoprotein recombinant virus vaccine, Proc Natl Acad Sci USA 81 (1984), pp. 7194-7198.

[11] C.E. Rupprecht and M.-P. Kieny, Development of a vaccinia-rabies glycoprotein recombinant virus vaccine. In: J.B. Campbell and K.M. Charlton, Editors, Rabies, Kluwer Academic Publishers, Boston (1988), pp. 335-364.

[12] J.W. Krebs, E.J. Mandel, D.L. Swerdlow and C.E. Rupprecht, Rabies surveillance in the United States during 2004, JAVMA 227 (2005) (12), pp. 1912-1925.

[13] C.L. Schumacher, P. Coulon, F. Lafay, J. Bénéjean, M.F.A. Aubert and J. Barrat et al., SAG-2 oral rabies vaccine, OJVR 60 (1993), pp. 459-462. 
[14] R.R. Redfield, D.C. Wright, W.D. James, T.S. Jones, C. Brown and D.S. Burke, Disseminated vaccinia in a military recruit with human immunodeficiency virus (HIV) disease, $N$ Engl J Med 316 (1987) (11), pp. 673-676.

[15] C.E. Rupprecht, L. Blass, K. Smith, L.A. Orciari, M. Niezgoda and S.G. Whitfield et al., Human infection due to recombinant vaccinia-rabies glycoprotein virus, $N$ Engl $J$ Med 345 (2001) (8), pp. 582-586.

[16] G.L. Smith, M. Mackett and B. Moss, Infectious vaccinia virus recombinants that express hepatitis B surface antigen, Nature 302 (1983), p. 490.

[17] M.E. Perkus, A. Piccini, B.R. Lipinskas and E. Paoletti, Recombinant vaccinia virus: immunization against multiple pathogens, Science 229 (1985), pp. 981-984.

[18] M.E. Andrew, B.E.H. Coupar and D.B. Boyle, Immunogenicity and antigen presentation. In: M.M. Binns and G.L. Smith, Editors, Recombinant poxviruses, CRC Press, Boca Raton (1992), pp. 207-234.

[19] F. Zavala, M. Rodrigues, D. Rodrigues, J. Rodrigues, R. Nussenzweig and M. Esteban, A striking property of recombinant poxviruses: efficient inducers of in vivo expansion of primed CD8+ T cells, Virology 280 (2001), pp. 155-159.

[20] P.-P. Pastoret and A. Vanderplasschen, Poxviruses as vaccine vectors. Comparative Immunology, Microbiol Infect Dis 26 (2003), pp. 343-355.

[21] T. Dudek and D.M. Knipe, Replication-defective viruses as vaccines and vaccine vectors, Virology 344 (2006), pp. 230-239.

[22] M. Fekadu, J.H. Shaddock, J.W. Sumner, D.W. Sanderlin, J.C. Knight and J.J. Esposito et al., Oral vaccination of skunks with raccoon poxvirus recombinants 
expressing the rabies glycoprotein or the nucleoprotein, J Wild Dis 27 (1991) (4), pp. 681-684.

[23] L. Hu, C. Ngicabe, C.V. Trimarchi, J.J. Esposito and F.W. Scot, Raccoon poxvirus live recombinant feline panleukopenia virus VP2 and rabies virus glycoprotein bivalent vaccine, Vaccine 15 (1997) (12-13), pp. 1466-1472.

[24] L.F. Fries, J. Tartaglia, J. Taylor, E.K. Kauffman, B. Meignier and E. Paoletti et al., Human safety and immunogenicity of a canarypox-rabies glycoprotein recombinant vaccine: an alternative poxvirus vector system, Vaccine 14 (1996) (5), pp. 428-434.

[25] G. Sutter and C. Staib, Vaccinia vectors as candidate vaccines: the development of modified vaccinia virus Ankara for antigen delivery, Curr Drug Targets-Infect Disord 3 (2003), pp. 263-271.

[26] I. Drexler, C. Staib and G. Sutter, Modified vaccinia virus Ankara as antigen delivery system: how can we best use its potential?, Curr Opin Biotechnol 15 (2004), pp. $1-7$.

[27] T. Hanke, A.J. McMicheal, R.V. Samuel, L.A.J. Powell, L. McLoughlin and S.J. Crome et al., Lack of toxicity and persistence in the mouse associated with administration of candidate DNA and modified vaccinia virus Ankara (MVA)-based HIV vaccine for Kenya, Vaccine 21 (2002), pp. 108-114.

[28] V.S. Moorthy, S. McConkey, M. Robert, P. Gothard, N. Arulanantham and P. Degano et al., Safety of DNA and modified vaccinia virus Ankara vaccines against liverstage P. falciparum malaria in non-immune volunteer, Vaccine 21 (2003), pp. 19952000 .

[29] K.K.A. Van Rompay, J.L. Freenier, K.S. Cole, P. Earl, B. Moss and J.D. Stechbeck et al., Immunization of newborn rhesus macaques with simian immunodefiency virus 
(SIV) vaccine prolongs survival after oral challenge with virulent SIVmac251, J Virol 77 (2003) (1), pp. 179-190.

[30] K.J. Stittelaar, T. Kuiken, R.L. de Swart, G. Van Amerongen, H.M. Vos and H.G.M. Niesters et al., Osterhaus ADME. Safety of modified vaccinia virus Ankara (MVA) in immune-suppressed macaques, Vaccine 19 (2001), pp. 3700-3709.

[31] H. Meyer, G. Sutter and A. Mayr, Mapping of deletions in the genome of the highly attenuated vaccinia virus MVA and their influence on virulence, J Gen Virol 72 (1991), pp. 1031-1308.

[32] G. Antoine, F. Scheiflinger, F. Dorner and F.G. Falkner, The complete genomic sequence of the modified vaccinia Ankara strain: comparison with other orthopoxviruses, Virology 244 (1998), pp. 365-396.

[33] T.J. Blanchard, A. Alcami, P. Andrea and G.L. Smith, Modified vaccinia virus Ankara undergoes limited replication in human cells and lacks several immunomodulatory proteins: implications for use as a human vaccine, J Gen Virol 79 (1998), pp. 1159-1167.

[34] L.S. Wyatt, M.W. Carroll, C.P. Czerny, M. Merchilinsky, J.R. Sisler and B. Moss, Marker rescue of the host range restriction defects of modified vaccinia virus Ankara, Virology 251 (1998), pp. 334-342.

[35] G. Sutter and B. Moss, Nonreplicating vaccinia vector efficiently expresses recombinant genes, Proc Natl Acad Sci USA 89 (1992), pp. 10847-10851.

[36] M.W. Carroll and B. Moss, Host range and cytopathogenicity of highly attenuated MVA strain of vaccinia virus: propagation and generation of recombinant viruses in a nonhuman mammalian cell line, Virology 238 (1997), pp. 198-211. 
[37] I. Drexler, K. Heller, B. Wahren, V. Erfle and G. Sutter, Highly attenuated modified vaccinia virus Ankara replicates in baby hamster kidney cells, a potential host for virus propagation, but not in various human transformed and primary cells, J Gen Virol 49 (1998), pp. 347-352.

[38] J.C. Ramírez, M.M. Gherardi and M. Esteban, Biology of attenuated modified vaccinia virus Ankara recombinant vector in mice: virus fate and activation of B- and Tcell immune responses in comparison with the Western Reserve strain and advantages as a vaccine, J Virol 74 (2000) (2), pp. 923-933.

[39] B.R. Minev, F.L. Chavez and M.S. Mitchell, Cancer vaccines: novel approaches and new promise, Pharmacol Ther 81 (1999) (2), pp. 121-139.

[40] M.C. Bonnet, J. Tartaglia, F. Verdier, P. Kourlisky, A. Lindberg and M. Klen et al., Recombinant viruses as a tool for therapeutic vaccination against human cancers, Immunol Lett 74 (2000), pp. 11-25.

[41] M.W. Carroll, W.W. Overwijk, R.S. Chamberlian, S.A. Rosenberg, B. Moss and N.P. Restifo, Highly attenuated modified vaccinia virus Ankara (MVA) as an effective recombinant vector: a murine tumor model, Vaccine 15 (1997) (4), pp. 387-394.

[42] T. Hanke, T.J. Blanchard, J. Schneider, C.M. Hannan, M. Becker and S.C. Gilbert et al., Enhancement of MHC class I-restricted peptide-specific T cell induction by a DNA prime/MVA boost vaccination regime, Vaccine 16 (1998) (5), pp. 439-445.

[43] C.E. Gomez, D. Rodriques, J.R. Rodriquez, F. Abaitua, C. Duarte and M. Esteban, Enhanced CD8+ response against a V3 loop multi-epitope polypeptide (TAB13) of HIV1 Env after priming with purified fusion protein and booster with modified vaccinia virus Ankara (MVA-TAB) recombinant a comparison of humoral and cellular immune responses with the vaccinia virus Western Reserve (WR) vector, Vaccine 20 (2002), pp. 961-971. 
[44] J. Schneider, S.C. Gilbert, T.J. Blanchard, T. Hanke, K.J. Robson and C.M. Hannan et al., Enhanced immunogenicity for $\mathrm{CD} 8+\mathrm{T}$ cell induction and complete protective efficacy of malaria DNA vaccination by boosting with modified vaccinia virus Ankara, Nat Med 4 (1998) (4), pp. 397-402.

[45] G. González-Aseguinolaza, Y. Nakaya, A. Molano, E. Dy, M. Esteban and D. Rodrigues et al., Induction of protective immunity against malaria by priming-boosting immunization with recombinant cold-adapted influenza and modified vaccinia virus Ankara expressing a CD8 $+\mathrm{T}$ cell epitope derived from the circumsporozoite protein of Plasmodium yeoli, J Virol 77 (2003) (21), pp. 11859-11866.

[46] P. Dégano, J. Schneider, C.M. Hannan, S.C. Gilbert and A.V.S. Hill, Gene gun intradermal DNA immunization followed by boosting with modified vaccinia virus Ankara: enhanced CD8+ T cell immunogenicity and protective efficacy in the influenza and malaria models, Vaccine 18 (2000), pp. 623-632.

[47] I.A. Ramshaw and A.J. Ramsay, The prime-boost strategy: exciting prospects for improved vaccination, Immunol Today 21 (2000) (4), pp. 163-165.

[48] D.L. Woodland, Jump-start the immune system: prime-boosting comes of age, Trends Immunol 25 (2004) (2), pp. 98-104.

[49] R.I. Freshney, The culture of animal cells: a manual of basic technique (3rd ed.), Wiley Liss, New York (1994) pp. 127-147.

[50] O.R. Kaaden, S. Lange and B. Stiburek, Establishment and characterization of chicken embryo fibroblast clone LSCC-H32, In Vitro 18 (1982) (10), pp. 827-834.

[51] Sambrook J, Russell DW. Molecular cloning: a laboratory manual, 3rd ed., Cold Spring Harbor Laboratory Press, Cold Spring Harbor, New York, pp. 1.31-1.38. 
[52] C. Staib, M. Löwel, V. Erfle and G. Sutter, Improved host range selection for recombinant modified vaccinia virus Ankara, Biotechniques 34 (2003) (4), pp. 694-700.

[53] C. Staib, M. Drexler, S. Ohlmann, S. Wintersperger, V. Erfle and G. Sutter, Transient host range selection for genetic engineering of modified vaccinia virus Ankara, Biotechniques 28 (2000), pp. 1137-1148.

[54] D.B. Wallace and G.J. Viljoen, Immune responses to recombinants of South African vaccine strain of lumpy skin disease generated by using thymidine kinase gene insertion, Vaccine 23 (2003) (23), pp. 3061-3067.

[55] Weyer J. Immune responses to recombinant poxviruses expressing lyssavirus glycoprotein genes. University of Pretoria, Ph.D. thesis, 2006, p. 88.

[56] Moss B, Earl PL. Expression of proteins in mammalian cells using vaccinia viral vectors. In: Current Protocols in Molecular Biology. John Wiley and Sons, p. 16.15.116.15.5.

[57] Byrd CM, Hruby DE. Construction of recombinant vaccinia virus. in: Isaacs, SN., (Ed.), Vaccinia virus and poxvirology, Humana Press, Totowa New Jersey, p31-40.

[58] J. Esposito, R. Condit and J. Obijeski, The preparation of orthopoxvirus DNA, $J$ Virol Meth 2 (1981), pp. 175-179.

[59] L. Pasamontes, J. Gubser, R. Wittek and G.J. Viljoen, Direct identification of recombinant virus plaques by PCR, $J$ Virol Meth 35 (1991), pp. 137-141.

[60] D.J. Dean, M.K. Abelseth and P. Atanasiu, The fluorescent antibody test. In: F.-X. Meslin, M.M. Kaplan and H. Koprowski, Editors, Laboratory techniques in rabies (4th ed.), World Health Organization, Geneva (1996), pp. 88-95. 
[61] D.L. Lodmell, L.C. Ewalt, M.J. Parnell, C.E. Rupprecht and C.A. Hanlon, One-time intradermal DNA vaccination in ear pinnae one year prior to infection protects dogs against rabies, Vaccine 24 (2006) (4), pp. 412-416.

[62] J.S. Smith, P.A. Yager and G.M. Baer, A rapid fluorescent focus inhibition test (RFFIT) for determining rabies virus-neutralizing antibody. In: F.-X. Meslin, M.M. Kaplan and H. Koprowski, Editors, Laboratory techniques in Rabies (4th ed.), World Health Organization, Geneva (1996), pp. 181-192.

[63] F.G. Falkner and B. Moss, Transient dominant selection of recombinant vaccinia viruses, J Virol 64 (1990) (3), pp. 108-111.

[64] K.J. Stittelaar, L.S. Wyatt, R.L. De Swart, H.W. Vos, J. Groen and G. Van Amerongen et al., Protective immunity in macaques vaccinated with a modified vaccinia virus Ankara-based measles virus vaccine in the presence of passively acquired antibodies, J Virol 74 (2000) (9), pp. 4236-4243.

[65] F.M.N. Bertley, P.A. Kozlowski, S.-W. Wang, J. Chappelle, J. Patel and O. Sonuyi et al., Control of simian/human immunodeficiency virus viremia and disease progression after Il-2-augmented DNA-Modified Vaccinia virus Ankara nasal vaccination in nonhuman primates, J Immunol 172 (2004) (6), pp. 3745-3757.

[66] E. Ramsburg, N.F. Rose, P.A. Marx, M. Mefford, D.F. Nixon and W.J. Moretto et al., Highly effective control of an AIDS virus challenge in macaques by using vesicular stomatitis virus and modified vaccinia virus Ankara vaccine vectors in a single-boost protocol, J Virol 78 (2004) (8), pp. 3930-3940.

[67] L. De Waal, L.S. Wyatt, S. Yüksel, G. Van Amerongen, B. Moss and H.G.M. Niesters et al., Vaccination of infant macaques with a recombinant modified vaccinia virus Ankara expressing the respiratory syncytial virus $\mathrm{F}$ and $\mathrm{G}$ genes does not predispose for immunopathology, Vaccine 22 (2004), pp. 923-926. 
[68] B.S. Bender, C.A. Rowe, S.F. Taylor, L.S. Wyatt, B. Moss and P.A. Small, Oral immunization with a replication deficient recombinant vaccinia virus protects mice against influenza, J Virol 70 (1996), pp. 6418-6424.

[69] M.M. Gherardi and M. Esteban, Recombinant poxviruses as mucosal vaccine vectors, J Gen Virol 86 (2005) (11), pp. 2925-2936.

[70] I. Belyakov, B. Moss, W. Strober and J.A. Berzofsky, Mucosal vaccination overcomes barrier to recombinant vaccinia immunization caused by preexisting poxvirus immunity, Proc Natl Acad Sci USA 96 (1999), pp. 4512-4517.

[71] D.L. Lodmell, J.J. Esposito and L.C. Ewalt, Live vaccinia rabies virus recombinants, but not an inactivated rabies virus cell culture vaccine, protect B-lymphocyte deficient A/WySNJ mice against rabies: considerations of recombinant defective poxviruses for rabies immunization of immunocompromised individuals, Vaccine 22 (2004), pp. 33293333.

the Disclaimer: Use of trade names and commercial sources are for identification only and do not imply endorsement by the U.S. Department of Health and Human Services. Disclaimer: The findings and conclusions in this report are those of the authors and do not necessarily represent the views of the funding agency.

Corresponding author. Tel.: +27 124206322; fax: + 27124203266.

${ }^{1}$ Present address: Molecular Biology Section, Laboratory of Immunology, National Institute for Allergy and Infectious Diseases, National Institutes of Health, 10 Center Drive, Bethesda 20892, United States of America.

${ }^{2}$ Present address: Animal Production and Health Section, International Atomic Energy Agency, Vienna 1400, Austria. 